УДК 159.942+159.98:612.6:618+171:173:176

Лебедева Анастасия Сергеевна, магистрант кафедры психологии ЧАО «ВУЗ «Межрегиональная Академия управления персоналом», 02000, ул. Фрометовская, 2, г. Киев, Украина; nastiabenito0902@gmail.com; +38(066) 079$59-92$

ORCID ID 0000-0001-5214-5525

Коляденко Нина Владимировна, доктор медицинских наук, доцент, заведующая кафедрой общемедицинских дисциплин и психосоматики ЧАО «ВУЗ «Межрегиональная Академия управления персоналом», 02000, ул. Фрометовская, 2, г. Киев, Украина; nina-k@ukr.net; +38(067)756-72-57

ORCID ID 0000-0003-2099-0163

\title{
ВНУТРЕННЯЯ КАРТИНА ВОСПРИЯТИЯ ЖЕНЩИНОЙ СВОЕЙ БЕРЕМЕННОСТИ
}

\begin{abstract}
Анотація
Лебедєва А. С., магістрант кафедри психології ПрАТ «ВНЗ «МАУП»; Коляденко Н. В., доктор медичних наук, доцент, завідувач кафедри загальномедичних дисциплін і психосоматики ПрАТ «ВНЗ «МАУП»; м. Київ, Україна. Внутрішня картина сприйняття жінкою своєї вагітності.

Ключові слова: внутрішня картина вагітності.

Постановка проблеми. Перебіг вагітності і їі результат багато в чому залежать від того, як жінка сприймає і саму вагітність, і себе - свої зовнішні та внутрішні зміни - в цьому стані. Сучасна жінка в процесі реалізації своєї соціальної ролі, планування сім'ї та дітонародження, все частіше стикається 3
\end{abstract}


різноманітними соціальними, психологічними, і біологічними проблемами. У той же час, ці проблеми залишаються недостатньо розробленими в науковій літературі, що й обумовлює актуальність нашого дослідження.

Аналіз останніх досліджень і публікацій. Тема внутрішньої картини сприйняття жінкою своєї вагітності дуже важлива. Ставлення матері до майбутньої дитини впливає на його фізичний i психологічний розвиток, формування почуттів прихильності, любові, ніжності, на подальше життя як дитини, так і матері, їх взаємовідносини. Безліч негативних чинників, з якими стикається вагітна жінка, можна розділити на дві основні групи: 1) соціальнопсихологічні; 2) біологічні.

Формулювання мети статті. Мета роботи - проаналізувати, 3 якими психологічними проблемами стикається жінка «в положенні». Завдання: на основі аналізу джерел наукової літератури, інтернет-форумів і проведення психодіагностичних досліджень, виявити проблематику питань, які виникають у жінок «в положенні», а також особливості їх внутрішньої картини сприйняття своєї вагітності.

Виклад основного матеріалу. Методи дослідження: контент-аналіз наукової літератури, інтернет-джерел, аналітичний метод, психодіагностичний метод (опитування, анкетування). Нами була розроблена спеціальна анкета, за допомогою якої досліджено 56 жінок репродуктивного віку. В результаті, понад 80\% з них зізналися, що відчували страх перед пологами, боялися наступу цього періоду. При цьому, у $23(41,1 \%)$ з них були труднощі в сім'ї в зв'язку 3 ситуацією вагітності. 36 (64,3\%) опитаних жінок не оголошували про свою вагітність через страх, що скажуть рідні, і не знаючи, як же піднести цю новину іншим. Половина 3 досліджуваних жінок - 28 (50,0\%) - говорили, що був страх щодо роботи, подальшого розвитку кар'єри, а також, що зміняться відносини 3 друзями. 


\section{Висновки i перспективи подальших досліджень. При достатній}

кількості наукових публікацій, тема психологічних проблем, пов'язаних із вагітністю та пологами, залишається недостатньо вивченою та $є$ перспективною для подальших досліджень в цьому напрямку. Внутрішня картина сприйняття жінкою своєї вагітності пов'язана з безліччю міфів і породжучих їх страхів, що вимагає відповідного медико-психологічного супроводу і підтримки вагітної жінки та їі сімейного оточення протягом всієї вагітності, в до- і післяпологовий період. Консультації у психолога 3 підготовки до пологів, психологічний супровід вагітності, пологів та післяпологового періоду згодом позитивно позначиться на психологічному стані жінки, іiї ставлення до новонародженої дитини і подальшому плануванні сім'ї.

\section{Аннотация}

Лебедева А. С., магистрант кафедры психологии ЧАО «ВУЗ «МАУП»; Коляденко Н. В., доктор медицинских наук, доцент, заведующая кафедрой общемедицинских дисциплин и психосоматики ЧАО «ВУЗ «МАУП; г. Киев, Украина. Внутренняя картина восприятия женщиной своей беременности.

Ключевые слова: внутренняя картина беременности.

Постановка проблемы. Протекание беременности и ее результат во многом зависят от того, как женщина воспринимает и саму беременность, и себя - свои внешние и внутренние изменения - в этом состоянии. Современная женщина в процессе реализации своей социальной роли, планирования семьи и деторождения, все чаще сталкивается с разнообразными социальными, психологическими, и биологическими проблемами. В то же время, эти проблемы остаются недостаточно разработанными в научной литературе, что и обусловливает актуальность нашого исследования. 
Анализ последних исследований и публикаций. Тема внутренней картины восприятия женщиной своей беременности очень важна. Отношение матери к будущему ребенку влияет на его физическое и психологическое развитие, формирование чувства привязанности, любви, нежности, на последующую жизнь и его, и матери, их взаимоотношения.

Множество негативных факторов, с которыми сталкивается беременная женщина, можно разделить на две основные группы: 1) социальнопсихологические; 2)биологические.

Формулирование цели статьи. Цель работы - проанализировать, с какими психологическими проблемами сталкивается женщина «в положении». Задачи: на основе анализа источников научной литературы, интернет-форумов и проведения психодиагностических исследований, выявить проблематику вопросов, которые возникают у женщин «в положении», а также особенности их внутренней картины восприятия своей беременности.

Изложение основного материала. Методы исследования: контент-анализ научной литературы, интернет-источников, аналитический метод, психодиагностический метод (опрос, анкетирование). Нами была разработана специальная анкета, с помощью которой исследовано 56 женщин репродуктивного возраста. В результате, более 80\% из них признались, что испытывали страх перед родами, боялись наступления этого периода. При этом, у $23(41,1 \%)$ из них были трудности в семье в связи с ситуацией беременности. 36 (64,3\%) опрошенных женщин не объявляли о своей беременности из-за страха, что скажут родные, и не зная, как же преподнести эту новость остальным. Половина из исследуемых женщин - 28 (50,0\%) - говорили, что, был страх насчет работы, дальшейшего развития карьеры, а так же что изменятся отношения с друзьями. 
Выводы и перспективы дальнейших исследований. При достаточном количестве научных публикаций, тема психологических проблем, связанных с беременностью и родами, остается недостаточно изученной и является перспективной для дальнейших исследований в этом направлении. Внутренняя картина восприятия женщиной своей беременности связана с множеством мифов и порождающих их страхов, что требует соответствующего медикопсихологического сопровождения и поддержки беременной женщины и семейного окружения на всем протяжении беременности, в до- и послеродовый период. Консультации у психолога по подготовке к родам, психологическое сопровождение беременности, родов и послеродового периода впоследствии позитивно отразится на психологическом состоянии женщины, ее отношении к новорожденному ребенку и дальнейшем планировании семьи.

\section{Annotation}

Lebedeva A. S., undergraduate, Department of Psychology, The Private Joint-Stock Company Higher Educational Institution Interregional Academy of Personnel Management; Kyiv, Ukraine; Koliadenko N.V., PhD, MD, Associate Professor, Head of the Department of General Medical Disciplines and Psychosomatics, The Private Joint-Stock Company Higher Educational Institution Interregional Academy of Personnel Management; Kyiv, Ukraine. The Internal Picture of a Woman's Perception of Her Pregnancy.

Key words: internal picture of pregnancy.

Formulation of the problem. The course of pregnancy and its result largely depend on how the woman perceives the pregnancy itself and itself - its external and internal changes - in this state. The modern woman in the process of fulfilling her social role, family planning and childbearing, is increasingly faced with a variety of social, psychological, and biological problems. At the same time, these problems 
remain insufficiently developed in the scientific literature, which determines the relevance of our study.

Analysis of recent research and publications. The theme of the woman's internal picture of her pregnancy is very important. The attitude of the mother to the unborn child affects his physical and psychological development, the formation of feelings of affection, love, tenderness, the subsequent life of both him and the mother, their relationship.The many negative factors that a pregnant woman faces can be divided into two main groups: 1) socio-psychological; 2) biological.

Formulating the purpose of the article. Purpose of work: to analyze what psychological problems a woman faces "in position". Tasks: on the basis of the analysis of sources of scientific literature, Internet forums and psychodiagnostic research, to identify the issues that women have "in position", as well as the features of their internal picture of their pregnancy.

The presentation of the main material. Research methods: content analysis of scientific literature, Internet sources, analytical method, psychodiagnostic method (survey, questionnaire). We have developed a special questionnaire, with the help of which 56 women of reproductive age were examined. As a result, more than $80 \%$ of them admitted that they felt fear of childbirth, were afraid of the onset of this period. At the same time, $23(41.1 \%)$ of them had difficulties in the family due to the pregnancy situation. $36(64.3 \%)$ of the women surveyed did not announce their pregnancy because of fear of what their relatives would say, and not knowing how to present this news to others. Half of the women studied - $28(50.0 \%)$ - said that there was fear about work, further career development, and also that relations with friends would change.

Conclusions and prospects for further research. With a sufficient number of scientific publications, the topic of psychological problems associated with pregnancy and childbirth remains insufficiently studied and is promising for further research in 
this direction. The internal picture of a woman's perception of her pregnancy is associated with many myths and fears that generate them, which requires appropriate medical and psychological support and support for a pregnant woman and family environment throughout pregnancy, in the pre- and postpartum period. Consultations with a psychologist on preparation for childbirth, psychological support for pregnancy, childbirth and the postpartum period will subsequently positively affect the psychological state of the woman, her attitude to the newborn child and further family planning.

Ключевые слова: внутренняя картина беременности.

Постановка проблемы. Вопросам внутренней картины болезни посвящено много исследований, публикаций как в научной, так и в учебной литературе [14; 20]. Беременность - это физиологическое состояние женщины, поэтому говорить о внутренней картине болезни в данном случае не представляется правомочным. Однако протекание беременности и ее результат во многом зависят от того, как женщина воспринимает и саму беременность, и себя - свои внешние и внутренние изменения - в этом состоянии. Поэтому, по аналогии с внутренней картиной болезни, нам представляется возможным говорить о «внутренней картине беременности»,-термин был введен Е. Б. Айвазян [3;4]. Современная женщина в процессе реализации своей социальной роли, планирования семьи и деторождения, все чаще сталкивается с разнообразными социальными, психологическими, и биологическими проблемами [2]. В то же время, эти проблемы остаются недостаточно разработанными в научной литературе, что и обусловливает актуальность нашого исследования. 
Анализ последних исследований и публикаций. Тема внутренней картины восприятия женщиной своей беременности очень важна, ведь отношение матери к будущему ребенку (желанный или нет; любит его (ребенка), или нет; хотела делать аборт, или нет и т.д. и т.п.) влияет на его физические и психологическое развитие, формирование чувств привязанности, любви, нежности, на последующую жизнь и его, и матери, их взаимоотношения [15].

Существуют болезни, которые человек может получить еще до рождения, при этом физические и психологические факторы тксно взаимосвязаны. Психоаналитик Отто Ранк (Otto Rank), ученик и коллега Зигмунда Фрейда (Sigmund Freud), утверждал, что если устранить последствия родовой травмы, то пациента можно вылечить от невроза [21]. Несмотря на то, что за столь новаторские мысли коллеги исключили его из Венского психоаналитического сообщества, в дальнейшем пренатальная психология стала привлекать внимание все большего числа исследователей. Дошло до того, что в 1980-х годах психологи стали использовать психоделики для исследования памяти плода и в результате в один и тот же период три психиатра (Stanislav Grof, Athanassios Kafkalides, Frank Lake) опубликовали свои исследования [21]. Некоторые пункты из них обсуждаются, исследуются и используются по сей день, в частности:

- неродившийся ребенок может получить до рождения позитивную информацию, которая будет способствовать расцвету задатков, заложенных в генах,- но может быть и наоборот, негативная информация затормозит их проявление;

- можно проработать травмы, полученные до рождения, о которых мы даже не догадываемся, и это ключ для решения многих психических проблем; 
- тяжелое эмоциональное состояние матери во время беременности порождает трудности в дальнейшей жизни ребенка.

Проанализировав ряд источников научной литературы по данной проблеме [1-24], мы определили, что существует множество негативных факторов, с которыми сталкивается беременная женщина. Эти факторы можно разделить на две основные группы: 1) социально- психологические; 2) биологические.

К социально-психологическим факторам относится то, как воспринимают новость о беременности родители, родственники, друзья, знакомые и, конечно же, отец ребенка [5; 7]. Существует много интернет-форумов, где дают советы о том, как правильно преподносить эту новость окружающим $[6 ; 12 ; 13]$. Не всегда новость об ожидающемся пополнении в семье вызывает радостное «ожидание нового чуда». Иногда это воспринимается крайне негативно, и такая реакция близких отражается на самой женщине, становясь для нее невыносимой психологической пыткой [7]. Порой это приводит к тому, что женщину принуждают к совершению аборта: ультиматумами («я или ребенок»), угрозами (например: «я уйду от тебя, если не сделаешь аборт»), или говорят о том, что это «сломает ей жизнь», «зачем он тебе нужен», «а что подумают окружающие» и еще очень много подобных фраз [6;21]. Девушка оказывается под гнетом негативизма и прессинга $[5 ; 6 ; 16 ; 21]$.

Боязнь объявить окружающим о ситуации беременности, таким образом, является первой проблемой. Вот один из вопросов на интернет-форуме, отражающий страхи таких женщин [21]: «Мне вот что интересно: когда стоит сообщать о своей беременности своим родственникам или друзьям? Или пусть сами заметят... А если обидятся? Особенно родственники... Но если узнают, то просто замучают советами из благих побуждений. И что делать...». Как же устоять и не поддаться влиянию окружающих, как справиться с этим? 
Вторая социальная проблема заключается в том, что во время беременности женщина сталкивается с множеством советов типа «я знаю лучше», «тебе нельзя», «делай как тебе говорят» и т.п. Таких советчиков предостаточно на жизненном пути, и каждый хочет высказать свои советы «как правильно», и что бы ни делала женщина - все для них «не так». Если в первые месяцы беременности будущую мать опекают и «кормят советами» только близкие, то чем заметнее становится живот, тем больше «слетается» на него «доброжелателей», причем особенно ярые советчики - это те женщины, которые прошли этот путь и поэтому уверены, что у них достаточно опыта, чтобы указывать будущей маме [21]. Каждый старается рассказать, как правильно, и в результате на этой почве возникает множество мифов, в которых очень легко запутаться.

Третья социально-психологическая проблема, с которой сталкивается будущая мама,- это страх, как она будет дальше личностно развиваться, строить карьеру, приспосабливаться в социуме, ведь как прежде уже не будет и надо адаптироваться под новые условия. Здесь появляются страхи: «как же я буду дальше работать, гулять с друзьями», «изменится ли круг общения», или на прежних жизненных планах уже можно «поставить крест» [21].

Четвертая психосоциальная проблема - боязнь родов. Это очень распространённый страх у девушек, порой он перерастает в фобию, такую как токофобия, или малевзиофобия, которая определяется как специфическая фобия - патологическая боязнь родов, связанная с боязнью боли (апгофобией) или реже - со страхом возникновения бытовых или других сложностей $[11 ; 23]$. Также существует еще один вид фобии, такой как гравидофобия - навязчивый страх встречи с беременной; боязнь забеременеть. Она может возникать в результате пережитых стрессов: рождение мертвого ребенка, смерть роженицы, социальные проблемы, страх родить больного ребенка [10]. 
К пятой социальной проблеме относится нововведение, которое активно обсуждается в последнее время а законодательном уровне и вокруг которого ведется бурная дискуссия и в социуме, и на уровне общественных организаций: «отмена запрета на увольнение беременных женщин и родителей в период декретного отпуска» [18], что, в свою очередь, еще более усложняет социальную сторону женщин «в положении».

Теперь перейдем к биологическому фактору. Естественно, что в процессе внутриутробного развития ребенка женщина меняется, изменяется ее внешность и другие параметры $[7 ; 21]$, в том числе:

- повышается масса тела, т.к. большое значение имеет действие прогестерона на развитие жировой ткани беременной женщины. Запасание питательных веществ в жировой ткани во время беременности необходимо для обеспечения питания плода и образования молока в послеродовом периоде. В идеале женщина должна за беременность набрать не более 10-12 кг, тогда проще восстановить вес после беременности. Поэтому важно уделять внимание питанию, режиму труда и отдыха. С первых дней и до 10-й недели развитие беременности поддерживается за счет гормонов, секретируемых яичниками. Далее синтез гормонов осуществляется плацентой. Основным гормоном плаценты является эстриол, который играет важную роль в процессах роста и развития матки при беременности. Этот гормон стимулирует развитие кровеносных сосудов и улучшает снабжение плода кислородом и питательными веществами [24];

- повышается сонливость, раздражительность, усталость, как следствие работы защитных механизмов центральной нервной системы, направленных на предотвращение переутомления беременной. Эти симптомы могут быть вызваны определенным уровнем гормона прогестерона, который и сохраняет 
беременную от переутомления, готовит железы к лактации, расслабляет мышцы матки и кишечника, тормозит нервную систему от перевозбуждения;

- усиливается обмен веществ - при этом, соответственно, увеличивается потребление организмом питательных веществ, витаминов, растет концентрация глюкозы в крови и соответствующая выработка инсулина. Поэтому нужно контролировать все эти показатели, чтобы не пропустить патологические состояния;

- пигментация кожи, изменения в чертах лица, - эти симптомы могут быть связаны с выработкой гормонов меланотропина и соматотропина, что также проявляется в увеличении ширины костей, повышении пигментации кожи;

- усиливается кровоток, увеличивается пульс и давление, учащается дыхание, т.к. с развитием беременности усиливается нагрузка на внутренние органы: прежде всего, происходят изменения со стороны сердечно-сосудистой системы, т. к. появляется необходимость в перекачке большей порции крови, получении большего количества кислорода, необходимого для развития плода. Учащение дыхания связано также с поднятием диафрагмы за счет увеличения матки, что не дает развернуться нормальному дыхательному процессу;

- увеличивается в размерах матка - шейка матки заполняется густой слизью, закупоривающей полость канала шейки матки. Стенки влагалища разрыхляются, кости размягчаются, органы становятся более эластичными и податливыми для родового процесса;

- могут появляться растяжки, - сначала на месте растяжения кожа может быть краснее, а в послеродовом периоде на коже боковых частей живота появляются белые полосы;

- молочные железы становятся более напряженными - увеличиваются в размерах, при надавливании возможно появление молозива; 
- притупляются реакции на раздражители. Это происходит за счет того, что на уровне спинного мозга блокируются импульсы, исходящие от чувствительных рецепторов матки, чтобы головной мозг не реагировал на малейший раздражитель отторжением плода, что позволяет сохранить беременность и предупреждает преждевременные роды. Отмечено, что этот механизм срабатывает вплоть до 39 недели беременности [13].

Формулирование цели статьи. Цель работы: проанализировать, с какими психологическими проблемами сталкивается женщина «в положении».

Задачи: на основе анализа источников научной литературы, интернетфорумов и проведения психодиагностических исследований, выявить проблематику вопросов, которые возникают у женщин «в положении», а также особенности их внутренней картины восприятия своей беременности.

Изложение основного материала. Методы исследования: контент-анализ научной литературы, интернет-источников, аналитический метод, психодиагностический метод (опрос, анкетирование).

Нами была разработана специальная анкета, с помощью которой исследовано 56 женщин репродуктивного возраста. В результате, более $80 \%$ из них признались, что испытывали страх перед родами, боялись наступления этого периода. При этом, у $23(41,1 \%)$ из них были трудности в семье в связи с ситуацией беременности. 36 (64,3\%) опрошенных женщин не объявляли о своей беременности из-за страха, что скажут родные, и не зная, как же преподнести эту новость остальным. Половина из исследуемых женщин - 28 (50,0\%) говорили, что, был страх насчет работы, дальшейшего развития карьеры, а так же что изменятся отношения с друзьями.

Запечатление ребенком информации во время нахождения в утробе матери называется пренатальной, или фетальной, памятью. Больше всего на будущее плода воздействует эмоциональный аспект: психологическое 
состояние будущей матери влияет на всю дальнейшую жизнь ребенка [1; 19]. Если мать испытывает стресс, уровень кортизола, гормона стресса, повышается в околоплодных водах и оказывает воздействие на развитие ребенка в будущем. Психологи связывают многие состояния взрослого человека с тем, что происходит с матерью и ребенком еще до его рождения. На основании данных научной литературы $[1 ; 2 ; 8]$, можно выделить следующие группы расстройств:

- Неврологические расстройства. Депрессия во время беременности встречается, по данным статистики, в 1/10 случаев [12]. Было доказано, что дети, родившиеся у матерей с дородовой депрессией, имели низкую оценку по шкале Апгар, часто им были необходимы реанимационные действия после рождения. Кроме того, чем более выраженной была депрессия у матери, тем менее спокойным был ребенок. Считается, что такое состояние матери может привести к неврологическим проблемам и психическим расстройствам у детей в будущем $[3 ; 5 ; 17 ; 19]$.

- Ожирение и диабет, нарушения питания: по данным ряда исследователей, младенцы, матери которых недоедали во время беременности, впоследствии были более подвержены заболеваниям, связанным с нарушением обмена веществ и пищевым поведением, по сравнению с теми, чем те, укоторых дородовой период прошел в благоприятных условиях [16].

- Когнитивные расстройства. Тревожность не менее частое явление у женщин «в положении». Имеются публикации, в которых доказывается, что у детей, матери которых страдали от тревожных расстройств, память хуже, чем у сверстников, им труднее концентрироваться и запоминать информацию [16; 21]. Кроме того, часто наблюдалось нарушение привязанности между матерью и ребенком, особенно у мальчиков [16;21].

- Сексуальные проблемы. Существует мнение, что если во время беременности мать хотела ребенка другого пола, то в подростковом возрасте 
он может бессознательно переживать сложности со своей половой самоидентификацией. С началом же половой жизни возможно появление различных проблем (импотенция, фригидность, гомосексуальность) [16].

- Заниженная самооценка. Нежеланные дети также могут испытывать трудности во взрослой жизни. Они могут быть пессимистичны, обидчивы, с заниженной самооценкой. Такие люди часто жаждут общественного признания, им трудно чувствовать привязанность, нередко их мучают неврозы [16].

- СДВГ (синдром дефицита внимания и гиперактивности). Сильный стресс также оказывает большое влияние на плод, при этом результат зависит от конкретного срока беременности. Например, если стресс был перенесен в 1-м триместре, когда закладывается нервная система плода, то повышается риск шизофрении. Если же стрессовое событие произошло во 2-м или 3-м триместре, то более вероятна склонность к СДВГ [16].

• Аутизм. Дэвид Беверсдорф (David Beversdorf) долго изучал генетические причины аутизма. Однако позже он исследовал также социальнопсихологические факторы этого явления и неожиданно обнаружил, что во многих случаях матери испытывали сильнейшие стрессы (смерть близких, потеря работы и т. п.). Больше всего влиянию таких стрессов были подвержены еще не рожденные дети (21-32-я недели беременности и особенно период 2528-й недель) [16; 19]. Некоторые последствия такого рода, как это ни парадоксально, оказались эволюционно полезными. Например, в мире, полном опасностей, тревожный ребенок был более бдительным, а малыш с быстро переключающимся вниманием (СДВГ) обладал более быстрой моторикой. Но в современном мире некоторые из этих изменений могут создавать проблемы для ребенка и его семьи [19]. 
Сегодня психосоциальные проблемы, связанные с беременностью, привлекают внимание все большего числа специалистов - психологов, психиатров, психотерапевтов. Появляются тематические форумы в социальных сетях, где обсуждаются вопросы, как быть, если случились проблемы, связанные с психосоциальными аспектами беременности. Эта сторона, волнует женщин больше, чем психофизиологическая, хотя, конечно страхи родов встречаются достаточно часто. Многие врачи сталкиваются с вопросами, насколько сильно будет больно, и страхами, как протекает беременность, нет ли патологий, а если есть, стоит ли рожать такого ребенка?...

«Стоит ли рожать, когда нет денег?...»- это очень частый вопрос. Лидия Геворкян - психолог, кандидат медицинских наук, пишет, отвечая на такие вопросы, приведенные с различными примерами [6]: «Почему кто-то может растить детей без оглядки на деньги, а кто-то - нет? Это вопрос психологического комфорта в первую очередь. С точки зрения здравого смысла, полезно до рождения ребенка отложить определенные средства. Не на учебу в Лондоне, разумеется, а на непредвиденные нужды. Болезнь, увольнение родителей - это не стоит списывать со счетов. Зная, что «страховая подушка» у вас есть (на крайний случай!), вы будете чувствовать себя намного увереннее и спокойнее в повседневной жизни» [6].

«Стоит ли рожать, если уже есть 2-3 детей?...», «Стоит ли рожать в юном возрасте?...» [4; 6; 17]. Как мы можем наблюдать, проблем возникает очень много, гораздо больше, чем описано в этой статье, что делает тему данных исследований актуальной и перспективной для дальнейшего изучения.

Выводы. В связи с вышеизложенным, можно сделать следующие выводы. Прежде всего, при достаточном количестве научных публикаций, тема психологических проблем, связанных с беременностью и родами, остается недостаточно изученной и является перспективной для дальнейших 
исследований в этом направлении. Внутренняя картина восприятия женщиной своей беременности связана с множеством мифов и порождающих их страхов, что требует соответствующего медико-психологического сопровождения и поддержки на всем протяжении беременности, в до- и послеродовый период, причем как самой беременной женщины, так и ее семейного окружения. Предлагается проходить будущим мамам консультации у психолога по подготовке к родам, психологическое сопровождение беременности, родов и послеродового периода, для того, чтобы женщина комфортно прошла этот период в своей жизни, нашла решение социальных проблем и легче воспринимала биологические проблемы, что впоследствии позитивно отразится как на ее психологическом состоянии, так и на отношении к новорожденному ребенку и дальнейшем планировании семьи.

\section{Список використаних джерел:}

1. Абрамченко В. В. Метод перинатального виховання в акушерській практиці /В.В. Абрамченко, Н.П. Коноваленко // Зб. матер. конф. 3 перинатальної психології.- С.-Пб, 2000. С.31-32.

2. Абрамченко В. В. Підготовка до безпечного материнства / В. В. Абрамченко, І. А. Шамхалова.- СПб.: ЭЛБІ СПб., 2005. - 204 с.

3. Айвазян Є. Б. Тілесний та емоційний досвід в структурі внутрішньої картини вагітності, ускладненої акушерською та екстрагенітальною патологією / С. Б. Айвазян, Г. А. Аріна, В. В. Ніколаєва // Вісник МДУ, Сер. 14: Психологія.- 2002.- №3.

4. Айвазян Є. Б. Феномен внутрішньої картини вагітності в контексті культурно-історичного підходу / Є. Б. Айвазян // Матеріали I Міжнар. конфер. 3 
клінічної психології пам'яті Б. В. Зейгарник: Зб. тез [ред. А. Ш. Тхостов].- М.: Центр ЗМІ МДУ, 2001.- С. 20-21.

5. Анохіна А. А. Психопрофілактична підготовка вагітних до пологів / А.А. Анохіна // Медична Допомога, 1996.- №5.- С. 26-28.

6. Буравчикова Д. Чи треба народжувати жебрацтво? Скільки коштує дитина сьогодні / Дарія Буравчикова // Аргументи і факти: ФедеральнІй АИФ [Електронний ресурс].- режим доступу: https://aif.ru/health/children/16552]

7. Брутман В. I. Вплив сімейних факторів на формування девіантної поведінки матері / Брутман В. І., Варга А. Я, Хамітова І. Ю. // Психологічний журнал, 2000.- № 2.- С. 79- 87.

8. Васильєва Т. Н. Самопочуття на різних термінах вагітності / Т. Н. Васильєва // Проблеми соціальної гігієни, охорони здоров’я та історії медицини, 1999.- № 1.- C. 2022.

9. Василюк Ф. С. Психологія переживання (аналіз подолання критичних ситуацій) / Ф. Є. Василюк.- М.: Вид-во МДУ, 1984.-200 с.

10. Гравідофобія [Електронний ресурс].- режим доступу: https://ru.wikipedia.org/wiki/Гравидофобия

11. Доктор Петровъ. Здоров’я нації // ТОВ «Вид. дім «КарманЪ» : Популярний журнал про медицину, 2012.- № 3 (56).- С. 40.

12. Сльшова Катерина. Депресія під час вагітності: причини та наслідки для дитини / К. Сльшова // First Step: Розумний розвиток малюка до 3-хроків, 28 січня 2018 p. [Електронний ресурс].- режим доступу: http://ru.firststep.com.ua/article/depressiya-vo-vremya-beremennosti-prichiny-iposledstviya-dlya-rebenka

13. Інтерв’ю з лікарем акушером-гінекологом клініки «Добробут» Ксенією Грищук [Електронный ресурс].- режим доступу: https://sn.ua/ru/lady/zdorovye/ ginekologiya/kak-beremennost-vliyaet-na-zhenskiy-organizm-382563.html 
14. Лурія Р. А. Внутрішня картина хвороби та ятрогенні захворювання / Р. А. Лурія.- М.: «Медицина», 1977.- С. 37-52.

15. Мельников В. А. Вплив фізіопрофілактичної підготовки та індивідуальної підтримки на протікання вагітності, пологів і післяпологового періоду / В. А. Мельников, Л. С. Сухобокова // Зб. наук. праць, присвячених 90річчю Самарського державного медичного університету і 35-річчю кафедри акушерства і гінекології №2 СамДМУ «Сучасні аспекти вирішення медикосоціальних проблем репродуктивного здоров'я жінок».-Самара,2009.-С.140-142.

16. Нечаєва М. А. Психологічні фактори онтогенезу материнської сфери, внутрішньої картини вагітності та перинатального розвитку / Нечаєва М. А., Рибалова Л. Ф., Штрахова А. В.- Челябінськ: Взд.-во ПУрДУ, 2005.- С. 26-60 с.

17. Ніколаєва, В. В. Внутрішня картина вагітності / В. В. Ніколаєва // Вісник МДУ, 2004.- Сер. 14. Психологія.

18. Новий трудовий кодекс [Електронный ресурс]. - режим доступу: https://zik.ua/ru/news/2019/10/17/noviy_trudovoy_kodeks_kak_mogut_yzmenytsya_ uslovyya_truda_ukrayntsev_y_dlya_1670361.

19. Обухова Л. Ф. Дитяча психологія: теорії, факти, проблеми / Обухова Л. Ф.- М.: Трівола, 1995.- Гл. ІІІ. Психоаналітичні теорії дитячого розвитку [Электронный pecypc].- режим доступу: http://psylib.org.ua/books/obuhl01/ index.htm

20. Погранична психіатрія [ред. Ю.А. Александровський]. - М.: РЛС-2006. $1280 \mathrm{c}$.

21. Сім проблем зі здоров'ям, які ми отримуємо ще до народження / ADME [Електронний pecypc].- режим доступу: https://www.adme.ru/svobodapsihologiya/kak-sostoyanie-zhenschiny-pri-beremennosti-vliyaet-na-zhizn-eebuduschego-rebenka-2198565/ 
22. Сухобокова Л. С. Фізіопсихопрофілактична підготовка до пологів і іï вплив на вагітність, пологи та післяпологовий період / Л. С. Сухобокова // Матер. III регіонального наук. форуму «Мати й дитина».- М., 2009.- С. 263-264.

23. Токофобія [Електронный ресурс].- режим доступу: https://ru.wikipedia. org/wiki/Токофобия

24. Естріол [Електронный ресурс].- режим доступу: https://ru.wikipedia. org/wiki/Естріол

\section{References}

1. Abramchenko, V. V. Konovalenko, N. P. (2000), "Method of perinatal education in obstetric practice" Sbornik materialov konferentsii po perinatal'noy psikhologii, S.-Pb, pp. 31-32, Ru.

2. Abramchenko, V. V. Shamkhalova, L. A. (2005), Podgotovka $k$ bezopasnomu materinstvu [Preparing for safe motherhood], ELBI St. Petersburg, S.-Pb, Ru.

3. Ayvazyan, E. B. Arina, G. A. Nikolaev, V. V. (2002), "Body and emotional experience in the structure of the internal picture of pregnancy complicated by obstetric and extragenital pathology", Vestnik MGU, Ser. 14: Psikhologiya, vol. 3, Ru.

4. Ayvazyan, E. B. [ed. A. Sh. Tkhostov], (2001), "The phenomenon of the internal picture of pregnancy in the context of a cultural-historical approach", Materialy Í Mezhdunarodnoy konferentsii po klinicheskoy psikhologi pamyati B. V. Zeygarnik: Sbornik tezisov.- pp. 20-21, Ru.

5. Anokhina, A. A. (1996), "Psychoprophylactic preparation of pregnant women for childbirth", Meditsinskaya Pomoshch, vol. 5, pp. 26-28, Ru.

6. Buravchikova, D. "Is poverty necessary? How much a child costs today", Argumenty $i$ fakty: Federal'nyy AIF, [Online], available at: https://aif.ru/health/ children/16552], Ru. 
7. Brutman, V. I. Varga, a. Ya. Khamitova, I. Yu. (2000), "Influence of family factors on the formation of deviant behavior of the mother", Psikhologicheskiy zhurnal, vol. 2, pp. 79- 87, Ru.

8. Vasilieva, T. N. (1999), "Health at different stages of pregnancy", Problemy sotsial'noy gigiyeny, zdravookhraneniya i istorii meditsiny, vol. 1, pp. 20-22, Ru.

9. Vasilyuk, F. E. (1984), Psikhologiya perezhivaniya (analiz preodoleniya kriticheskikh situatsiy), [Psychology of experience (analysis of overcoming critical situations)], Publishing House of Moscow State University,Moscow, Ru.

10. "Gravidophobia" [Gravidophobia], [Online], available at: https://ru.wikipedia.org/wiki/ Gravidophobia, Ru.

11. Dr. Petrov, (2012), "Health of the Nation", OOO "Izdatel'skiy dom “Karman": Populyarnyy zhurnal o meditsine, vol. 3 (56), pp. 40, Ru.

12. Elshova K. (2018), "Depression during pregnancy: causes and consequences for the baby", First Step: Razumnoye razvitiye malysha do 3-kh let, [Online], available at: http://ru.firststep.com. ua / article / depressiya-vo-vremya-beremennostiprichiny-i-posledstviya-dlya-rebenka, $\mathrm{Ru}$.

13. Interview with the doctor, obstetrician-gynecologist of the Dobrobut clinic Ksenia Grischuk, [Online], available at: https://sn.ua/ru/lady/zdorovye/ ginekologiya/kak-beremennost-vliyaet-na-zhenskiy-organizm -382563.html, Ru.

14. Luria, R. A. (1977), Vnutrennyaya kartina bolezni i iatrogennyye zabolevaniya [The internal picture of the disease and iatrogenic diseases], "Medicine", Moscow, pp. 37-52, Ru.

15. Melnikov, V. A. Sukhobokova, L. S. (2009), "Influence of physioprophylactic preparation and individual support on the course of pregnancy, childbirth and the postpartum period", Sb. nauch. trudov, posvyashchennyy 90-letiyu Samarskogo gosudarstvennogo meditsinskogo universiteta $i$ 35-letiyu kafedry akusherstva $i$ 
ginekologii №2 SamGMU «Sovremennyye aspekty resheniya mediko-sotsial'nykh problem reproduktivnogo zdorov'ya zhenshchin, Samara, pp.140-142, Ru.

16. Nechaeva, M. A. Rybalova, L. F. Strakhova, A. V. (2005), Psikhologicheskiye faktory ontogeneza materinskoy sfery, vnutrenney kartiny beremennosti $i$ perinatal'nogo razvitiya [Psychological factors of ontogenesis of the maternal sphere, the internal picture of pregnancy and perinatal development], Publishing House of SUSU, Chelyabinsk, pp. 26-60, Ru.

17. Nikolaeva, V. V. (2004), "The internal picture of pregnancy", Vestnik $M G U$, Ser. 14. Psychology, Ru.

18. The new labor code (2019), [Online], available at: https://zik.ua/en/news/ 2019/10/17/noviy_trudovoy_kodeks_kak_mogut_yzmenytsya_uslovyya_truda_ukray ntsev_y_dlya_1670361, Ru.

19. Obukhova, L. F. (1995), Detskaya psikhologiya: teorii, fakty, problemy, Gl. IIÍI. Psikhoanaliticheskiye teorii detskogo razvitiya [Children's psychology: theories, facts, problems, Ch. III. Psychoanalytic theory of child development], Trivola, Moscow, [Online], available at: http://psylib.org.ua/books/obuhl01/index.htm, Ru.

20. "Pogranichnaya psikhiatriya” [Borderline Psychiatry [Ed. Alexandrovsky Yu.A.], (2006), RLS-2006, Moscow, Ru.

21. "Sem' problem so zdorov'yem, kotoryye my poluchayem yeshche do rozhdeniya", [ Seven health problems that we get before birth], [Online], available at: ADME, https://www.adme.ru/svoboda-psihologiya/kak-sostoyanie-zhenschiny-priberemennosti-vliyaet- na-zhizn-ee-buduschego-rebenka-2198565 /, Ru.

22. Sukhobokova, L. S. (2009), "Physiopsychopreventive preparation for childbirth and its effect on pregnancy, childbirth and the postpartum period", Materialy ÍÍI regional'nogo nauchnogo foruma «Mat' $i$ ditya», pp. 263 -264, Ru.

23. "Tokofobiya” [Tokophobia], [Online], available at: https://ru.wikipedia.org/ wiki/Tocophobia, Ru.
24. "Estriol”
[Estriol],
[Online],
available
at:

https://ru.wikipedia.org/wiki/Estriol, Ru. 